\title{
O diagnóstico genético de pré-implantação: o direito e a dignidade da pessoa humana
}

DOI: 10.47224/revista master.v6i11.115

Geilson Nunes

Giovanna de Menezes Bernardo

e-mail:giomenber@hotmail.com

\section{Resumo}

A presente pesquisa teve por objetivo o estudo sobre o diagnóstico de pré-implantação, procurando demonstrar os avanços tecnológicos no campo genético, seus aspectos positivos, negativos e a problemática em torno de sua regulação legal e principiológica. Inicialmente, buscou-se aclarar os conceitos e eficácia dos princípios fundamentais humano, trazendo o debate em torno do assunto. Em seguida tratou-se do conceito e utilização do diagnóstico de pré-implantação, a questão dos limites da biotecnologia em relação ao direito e da tutela do direito da personalidade do nascituro in vitro e os impactos biotécnicos. O método de abordagem seguido foi o dialético, utilizando-se de um referencial teórico constitucional, legal e doutrinário.

Palavras-chave: Biotecnologias; Dignidade da pessoa humana; Direitos fundamentais; Intervenções genéticas.

\section{Abstract}

The objective of this research was to study the pre-implantation diagnosis, seeking to demonstrate technological advances in the genetic field, its positive and negative aspects and the problems surrounding its legal and principiological regulation. Initially, we sought to clarify the concepts and effectiveness of the fundamental human principles, bringing the debate around the subject. Next, the concept and use of the pre-implantation diagnosis was addressed, the question of the limits of biotechnology in relation to the right and protection of the right of the unborn child in vitro and the biotechnical impacts. The method of approach followed was dialectical, using a constitutional, legal and doctrinal theoretical framework.

Keywords: $\quad$ Biotechnologies; Dignity of human person; Fundamental rights; Genetic interventions.

\section{INTRODUÇÃO}

O objetivo da presente pesquisa será proceder um estudo do diagnóstico de pré-implantação, em razão dos avanços tecnológicos de pesquisas em célulastronco embrionárias que no Brasil se popularizou sem prévia regulamentação, ocasionando questões de difícil resolução na esfera jurídica e prática.

Nesse sentido, inicialmente tratar-se-á da questão dos direitos fundamentais e do princípio da dignidade da pessoa humana, seus aspectos constitucionais, conceituais e sociais, a aplicabilidade e eficácia destes distinguindo-se o conceito de direitos fundamentais de direitos humanos, em consonância com o que se preconiza no art. 5o da Constituição Federal de 1988, demonstrando sua importância para o alcance dos fundamentos da República, por meio de condutas positivas e socialmente inclusivas, a fim de garantir a todos os direitos intrínsecos a toda pessoa, afastando das condutas abusivas, e que acarrete em conflitos morais, sociais e materiais a garantir a existência de vida digna para as presentes e futuras gerações.

$\mathrm{Na}$ sequência, a atenção será dada quanto ao conceito e utilização do diagnóstico préimplantacional, atividade que não deve interferir na integralidade do embrião. Caso essa técnica constitui práticas inconstitucionais a demonstrar interesses de um ser humano sob o outro.

Demonstrando que embrião tem a guarida constitucional e se os fins desta técnica não forem terapêuticas, existe um aparato legal e 
principiológico para a sua contenção em nome do interesse individual e público.

Por fim, busca-se demonstrar que o embrião in vitro é sujeito de direito o qual tem que ser inerente a este a personalidade jurídica visto se tratar de uma vida em formação.

Quanto ao objetivo a ser alcançado, pretender-se-á esclarecer que ainda não existe regulamentação legal que busca contribuir e fiscalizar o desenvolvimento de pesquisas no campo genético, em respeito aos direitos fundamentais humanos, e dignidade da pessoa humana, devendo resguardar os limites principiológicos do texto constitucional e se abster de condutas que configurem abuso de direito em abandono ao ideal individualista.

Para a obtenção dos resultados almejados na presente pesquisa, o método de abordagem utilizado será o dialético, a partir de um diálogo das diversas fontes pesquisadas que tratam do tema, de forma a alcançar os resultados propostos. A metodologia de investigação utilizada será a pesquisa de caráter essencialmente bibliográfico.

\section{DIGNIDADE DA PESSOA HUMANA E DIREITOS FUNDAMENTAIS: UM OLHAR NA SAÚDE}

Os direitos e as garantias fundamentais são encontrados na Constituição Federal de 1988 em seu Título II, é relevante compreender a diferença entre direitos e garantias fundamentais, que muitas das vezes partem do pressuposto que se trata de sinônimos, dessa maneira faz-se necessária uma análise em seus conceitos e aplicabilidade. A respeito Sarlet $(2015, n$. p) narra que:

Em caráter ilustrativo, encontramos em nossa Carta Magna expressões como: a) direitos humanos (art. 4으, inc. II; b) direitos e garantias fundamentais (epígrafe do Título II, e art. 5으 $\S 1$ 의); c) direitos e liberdades constitucionais (art. 50, inc. LXXI) e d) direitos e garantias individuais (art. 60, §4으, inc. IV).

Ensina Sarlet (2015) que é indispensável a fundamentação do termo "direitos fundamentais", mesmo que seja sumária, mas que podem ser, pelo ponto de vista doutrinário, quanto no direito constitucional ou internacional muitas expressões como "direitos humanos", "direitos do homem", "liberdades fundamentais", "direitos humanos fundamentais", entre outras.

Ainda de acordo com Sarlet (2015), o título II da Constituição Federal de 1988 se refere aos Direitos e Garantias Fundamentais, tal termo é genérico e abrange as demais categorias de direitos fundamentais, nomeadamente os direitos e deveres individuais e coletivos (Capítulo I), os direitos sociais (Capitulo II), a nacionalidade (Capítulo III), os direitos políticos (Capítulo IV) e o regramento dos partidos políticos (Capítulo V), vale ressaltar que essas categorias englobam diferentes aplicações exercidas pelos direitos fundamentais.

Não há dúvidas de que os direitos fundamentais são direitos humanos, pois o titular desse direito é o ser humano, mesmo que seja representado por grupos, povos, nações ou Estado.

Os termos direitos humanos e direitos fundamentais são tidos como sinônimos, no entanto, há uma distinção entre eles, sendo dos direitos fundamentais aqueles reconhecidos positivamente na Constituição de determinado Estado, enquanto direitos humanos, tutela ligação com os tratados, documentos de direito internacional. Sobre a relevante fundamentação sobre direitos humanos, Sarlet (2015, n.p) faz a seguinte afirmação:

\begin{abstract}
[...] ao passo que a expressão "direitos humanos" guardaria relação com os documentos de direito internacional, por referir-se àquelas posições jurídicas que se reconhecem ao ser como tal, independentemente de sua vinculação com determinada ordem constitucional, e que, portanto, aspiram à validade universal, para todos os povos e tempos, de tal sorte, que relevam um inequívoco caráter supracional (internacional).
\end{abstract}

O termo "direitos do homem", de sentido marcadamente jus naturalista, aplica-se de maneira que torna necessária a limitação entre a concepção contemporânea dos direitos fundamentais e humanos que devido sua relevância contribuiu para a positivação dos direitos fundamentais.

Os direitos humanos (ou direitos dos homens) são direitos essenciais e típicos à natureza humana, estando eles positivados ou não na lei, distinguindose dos direitos fundamentais os quais constam em tratados internacionais e nas constituições, 
possuindo eficácias e proteção diferenciados. Acerca da relação entre os direitos fundamentais e os direitos humanos, Sarlet $(2015$, n.p), ensina:

Reconhecer a diferença, contudo, não significa desconsiderar a íntima relação entre os direitos humanos e os direitos fundamentais, uma vez que a maior parte das Constituições do segundo pós-guerra se inspirou tanto na Declaração Universal de 1948, quanto nos diversos documentos internacionais e regionais que as sucederam, de tal sorte que - no que diz com o conteúdo das declarações internacionais e dos textos constitucionaisestá ocorrendo um processo de aproximação e harmonização, rumo ao que já está sendo denominado (e não exclusivamente - embora principalmente , no campo dos direitos humanos e fundamentais) de um direito constitucional internacional.

Acerca da referida discussão Sarlet (2015) aduz qual é a melhor expressão a ser adotada, tem-se que o uso da terminologia mais recorrente é "direitos humanos fundamentais", a qual tem a vantagem em ressaltar a unidade essencial e indissolúvel entre direitos humanos e direitos fundamentais. No entanto, tendo relevância na distinção entre seus critérios, aponta a fundamentalidade material e formal, sendo este comum aos direitos humanos e fundamentais constitucionais

Na Bíblia Sagrada no Livro de Gênesis capítulo 1 versículo 26 , relata que a humanidade carrega a imagem de Deus, dizendo: "Também disse Deus: Façamos o homem à nossa imagem, conforme a nossa semelhança...", na passagem não é especificado de que modo os seres humanos carregam a similaridade com Deus, mas não há o que negar sobre a grande importância do ser humano, visto que todas as vidas têm o mesmo valor e cada uma sua importância.

Habermas (2010, p. 51-52) ensina ainda que em algumas fases da vida humana são consideradas não pessoal, mas devem ser consideradas com dignidade e respeito:

[...] O caráter dos entraves morais, difíceis de definir, que regulam o trato com a vida humana antes do nascimento e após a morte explica a escolha de expressões semanticamente flexíveis. A vida humana também desfruta, em suas formas anônimas, de "dignidade" e exige "respeito". Se podemos recorrer ao termo "dignidade", é porque ele cobre um amplo espectro semântico e apenas evoca o conceito mais específico da dignidade humana.

O princípio da dignidade da pessoa demonstra que nenhuma vida humana deveria ser considerada como um simples meio, mas como um fim, usar embriões humanos na investigação genética em que o fim não seja terapêutico, é uma violação ao princípio da dignidade da pessoa humana, dado que é uma instrumentalização da vida humana, e a dignidade é um atributo da vida humana.

No preceito constitucional art. 50 §2은 Sarlet (2015) diz que se refere ás disposições contidas no arts. 10 a 4으, Título I (Dos princípios Fundamentais), em que também se encontra as configurações do Estado social e democrático de Direito que identifica a República Federativa do Brasil

A Constituição Federal de 1988 consagra o regime de governo democrático no Brasil, em que se encontram expressos os objetivos, fundamentos e princípios fundamentais que regem o Estado brasileiro, de nível interno e internacional. Sobre essa relevante afirmação, Sarlet (2015 n.p), assegura:

Assim, verifica-se que os direitos fundamentais decorrentes do regime e dos princípios, conforme denominação expressamente outorgada pelo art. 5으 §2응 da CF, são posições jurídicas material e formalmente fundamentais fora do catálogo (Título II), diretamente deduzidas do regime e dos princípios fundamentais da Constituição[...].

Os direitos fundamentais e os direitos não escritos guardam relação entre si, mesmo divergindo-se quanto ao seu conteúdo e eficácia com os princípios fundamentais da Constituição Federal, dessa maneira não há como negar que os direitos à vida, liberdade e igualdade conferem às determinações essenciais da dignidade da pessoa humana.

Sobre o princípio da dignidade da pessoa humana Sarlet (2015), ensina que os direitos fundamentais por seu conteúdo baseado no princípio da dignidade da pessoa humano, é alcançado pela recognição e 
positivação dos direitos e garantias fundamentais. Todos os direitos fundamentais encontram sentido no princípio da dignidade da pessoa humana.

Em que pese a importante função do princípio da dignidade da pessoa humana, ora item referencial para análise e aplicação dos direitos, seja na circunstância de fundamento para o silogismo de direitos fundamentais decorrentes.

A Constituição Federal de 1988, foi a primeira a prever um título com destinação a dispor de princípios fundamentais, diante disto o constituinte intencionalmente outorgar aos princípios fundamentais a peculiaridade de normas que respaldam e informam toda a ordem constitucional até mesmo os direitos fundamentais que fazem parte da Constituição Federal.

No art.1ำ, inciso III, da Constituição Federal de 1988, é reconhecido no âmbito do direito positivo, o princípio fundamental da dignidade da pessoa humana, o qual não foi previsto em direito anterior. A valorização da dignidade da pessoa humana foi instrumento que estabeleceu a ordem econômica, assegurando que todos tenha uma existência digna, fundando o planejamento familiar e da paternidade responsável. Nesse sentindo Sarlet (2015 n.p) assevera:

[...] o valor da dignidade da pessoa humana foi objeto de previsão por parte do Constituinte, seja quando estabeleceu que a ordem econômica tem por fim assegurar a todos uma existência digna (art. 170, caput), seja quando, no âmbito da ordem social, fundou o planejamento familiar nos princípios da dignidade da pessoa humana e da paternidade responsável (art. 226, $\S 60$ ), além de assegurar à criança e ao adolescente o direito à dignidade (art. 227, caput). Assim, ao menos neste final de século, o princípio da dignidade da pessoa humana mereceu a devida atenção na esfera do nosso direito constitucional.

Não há como ignorar a linha filosófica e histórica do princípio e sua relação intimista com a doutrina jus naturalista, ainda ao atribuir ao princípio da dignidade da pessoa humana compre ressaltar que o valor da pessoa humana encontra enraizado no pensamento e ideologia cristã, tendo como premissa que o homem foi criado à imagem e semelhança de Deus extraindo a consequência de que o ser humano é dotado de um valor próprio, não podendo ser instrumentalizado ou coisificado.

Conclui-se que todos os seres humanos são dotados da mesma dignidade, visto que é um atributo inerente ao ser humano, o distinguindo das demais criaturas. Noção está sustentada pela filosofia estoica que vincula o princípio a como o homem é responsável e livre por seus atos e destino.

Ao citar Immanuel Kant, Salert (2015) diz que na concepção dele, considerando a autonomia do ser humano, sua concepção de dignidade parte da ética do ser humano, a qual sustenta que o indivíduo não pode ser tratado como objeto nem por ele mesmo.

Não resta dúvidas de que a dignidade é algo real, a doutrina e a jurisprudência estabelecem conceitos básicos para concretizar o seu conteúdo, ainda que não se fale de uma definição genérica $e$ consensualmente aceita, costuma-se mencionar que o princípio da dignidade da pessoa humana é uma categoria axiológica aberta, sendo errôneo conceituá-lo de forma fixista.

Vale ressaltar que a dignidade, como qualidade inerente da pessoa humana, é algo que existe sendo simplesmente irrenunciável e inalienável, na proporção em que constitui elemento que qualifica o ser humano como tal, sendo algo que se protege, respeita e reconhece, não podendo ser criado ou retirado, já que é intrínseco a cada ser humano.

\section{O DIAGNÓSTICO GENÉTICO DE PRÉ- IMPLANTAÇÃO}

Desde o século XIX a medicina está em progresso, seus métodos de pesquisa têm constituído até mesmo uma promessa de prolongamento da expectativa de vida humana. Acredita-se que a realização do exame pré-implantatório não promove alteração do desenvolvimento do embrião, mas ainda é considerado um procedimento experimental.

Habermas (2010, p. 23) ensina que em 1973, foi possível a separação e a volta na combinação de componentes elementares de um genoma, sendo essa recombinação artificial, a técnica genética na medicina reprodutiva empregada nos procedimentos do diagnóstico pré-natal, e mais tarde em 1978 foi aplicada a técnica na inseminação artificial. 
O Diagnóstico genético pré-implantacional (DGPI) é uma técnica realizada em embriões que se encontram num estágio de oito células obtidos pela técnica de fertilização in vitro (FIV) que permite a análise genética de precaução antes de ser implantado no útero.

Segundo Habermas (2010, p. 24), no início o procedimento é colocado ao domínio de pais que querem evitar o risco da transmissão de doenças hereditárias. Vindo a ser confirmada algum tipo de doença, o embrião analisado na proveta poderá não ser reimplantado na mãe; desse modo, ela é poupada de uma futura interrupção da gravidez, que do contrário, seria efetuada após o diagnóstico pré-natal.

A técnica é de utilização legítima se o objetivo for terapêutico, que não ofenda a integridade do embrião, ou como aconselhamento a gestação, no caso de prepará-la contra os riscos. Contudo, existe o debate entre a liberdade de escolha dos pais sobre o embrião, e o direito à vida do pré-implantacional (in vitro).

No ano de 1997, em seu art. 13, o convênio Europeu de Direitos Humanos e Biomedicina, afirmou que:

\begin{abstract}
Uma intervenção que tenha por objeto modificar o genoma humano não pode ser levada a efeito senão por razões preventivas, de diagnóstico ou terapêuticas e somente se não tiver por finalidade introduzir uma modificação no genoma da descendência.
\end{abstract}

O direito tem-se afligido com a tutela do nascituro sob a perspectiva patrimonialista. No entanto, 0 atual conceito de nascituro, a colocar igualdade de tratamento entre o concepto pré-implantatório e o concepto já implantado no útero, inspira-se numa linha não patrimonialista.

Através do diagnóstico genético de préimplantação, Habermas (2010, p. 29), ensina que atualmente já é difícil respeitar o limite entre a seleção de fatores hereditários indesejáveis e o aperfeiçoamento desejável.

No atual contexto dos avanços tecnológicos, a interpretação não deve melindrar-se ao afirmar que o concepto-implantacional, por sua natureza, é vida humana, esteja in vitro ou criopreservado.
Todo o sistema jurídico é a expressão de um sistema de valores concretos, em consequência, na atual conjuntura é perceptível que as ciências da vida necessitam de uma regulação que nos garanta que os grandes parâmetros éticos compartilhados por grupos sociais sejam respeitados em todos os momentos, sobre tal importância, Habermas (2010, p. 28-29) nos indaga a certa maneira que:

A aplicação da técnica de pré-implantação vincula-se a seguinte questão normativa: É compatível com a dignidade humana ser gerado mediante ressalva e, somente após um exame genético, ser considerado digno de uma existência e de um desenvolvimento? Podemos dispor livremente da vida humana para fins de seleção? Uma questão semelhante se faz quanto aos aspectos do "consumo" de embriões (inclusive a partir das próprias células somáticas) para suprir a vaga de um dia poder-se produzir e enxertar tecidos transplantáveis, sem ter de enfrentar o problema de transpor barreiras da rejeição a células estranhas.

Obstáculo ao qual o direito só pode dar resposta por meio da interdisciplinaridade, as grandes possibilidades que se abrem diante de todo ser humano são motivo de alegria e otimismo, por outro lado é inevitável a agitação acerca aos possíveis desastres de que uma má interpretação dos valores em jogo ou o emprego inadequado dos novos conhecimentos e tecnologias que surgem poderiam causar.

Não obstante, os legisladores se defrontam, em relação a novas tecnologias, com um problema que poderia qualificar como a incerteza na hora de definir os verdadeiros riscos que devem prevenir e que podem estar vinculados a essas tecnologias. A Resolução do Conselho Federal de Medicina no 1.358/92 veda o descarte dos embriões excedentários, no seguinte termo:

O número total de pré-embriões produzidos em laboratório será comunicado aos pacientes, para que se decida quantos pré-embriões serão transferidos a fresco, devendo o excedente ser criopreservado, não podendo ser descartado ou destruído. 
Nos dias atuais, ainda não há legislação brasileira específica, que trata do diagnóstico préimplantacional, no entanto a Resolução 1.957/2010 do Conselho Federal de Medicina, dispõe em seus princípios das técnicas realizadas de reprodução assistida que não devem ser empregues para selecionar sexo, ou qualquer outra característica biológica do futuro filho que vier a nascer:

As técnicas de RA também podem ser utilizadas na preservação e tratamento de doenças genéticas ou hereditárias, quando perfeitamente indicadas e com suficientes garantias de diagnóstico e terapêutica

1 - Toda intervenção sobre embriões "in vitro", com fins diagnósticos, não poderá ter outra finalidade que não a de avaliar sua viabilidade ou detectar doenças hereditárias, sendo obrigatório o consentimento informado do casal.

2 - Toda intervenção com fins terapêuticos sobre embriões "in vitro" não terá outra finalidade que não a de tratar uma doença ou impedir sua transmissão, com garantias reais de sucesso, sendo obrigatório 0 consentimento informado do casal.

3 - O tempo máximo de desenvolvimento de embriões "in vitro" será de 14 dias.

Ainda, a Lei 11.105/05 em seu art. 5으, dispõe que não há permissão, nem vedação expressa ao descarte de embriões humanos. Dessa maneira, observa-se que há controvérsias, sobre o destino e estudo em embriões e embriões excedentes.

Na Ação Direta de Inconstitucionalidade discutiu-se a constitucionalidade do art. 5o da Lei de Biossegurança (no 11.105/05), o relator Carlos Ayres Britto qualificou a Lei de Biossegurança como um "perfeito" e "bem concatenado bloco normativo". Sustentou a tese de que, para existir vida humana, é preciso que o embrião tenha sido implantado no útero humano. Segundo ele, tem que haver a participação ativa da futura mãe.

Ele se reportou, também, a diversos artigos da Constituição que tratam do direito à saúde (artigos 196 a 200) e à obrigatoriedade do Estado de garantila, para defender a utilização de células-tronco embrionárias para o tratamento de doenças.

Diversamente, o Ministro Carlos Alberto Menezes Direito julgou a ação parcialmente procedente. Segundo Menezes Direito, "as pesquisas com as células-tronco podem ser mantidas, mas sem prejuízo para os embriões humanos viáveis, ou seja, sem que sejam destruídos".

O Ministro demonstra na ADI 3510 (STF, 2011, p. $110,111,113$ e 130) preocupação no emprego do diagnóstico genético pré-implantacional:

É claro que a adoção dessa técnica não deixa margem à ilusão. Se os embriões cujo diagnóstico é negativo são implantados $e$ nascerão com a certeza de que não sofrerão das anomalias pesquisadas, é certo que aqueles cujo diagnóstico é positivo não serão escolhidos para implantação. Pior, serão, na grande maioria dos casos, simplesmente descartados. É a realidade da seleção gênica, um grande fantasma da manipulação de embriões

[...] Quando o decreto regulamentar da lei sob exame menciona, por exemplo, a qualificação da inviabilidade do embrião com alterações genéticas ou alterações morfológicas, abre campo minado para a eugenia, que sob nenhum aspecto pode ser tolerada. Admitir que as clínicas de reprodução assistida sejam as responsáveis pela identificação das alterações genéticas e morfológicas para descartar os embriões, equivale a investi-las de poder absoluto sobre o que pode, ou não, desenvolver-se autonomamente até o nascimento com vida. Esse poder, certamente, não nos pertence.

[...] Será possível deixar de enxergar a gravidade do cenário montado, por exemplo, pelas técnicas de diagnóstico genético de embriões, em que se torna possível selecionar geneticamente aqueles que mereçam seguir adiante, descartando os demais, por que portadores de defeito genético? Isso quer dizer que é possível descartar aqueles embriões em que se diagnostica a trissomia do cromossomo 21 , como se os portadores de Síndrome de Down não tivessem o direito de viver. $A$ busca da eugenia, da raça pura, do ser humano programado em laboratórios, não é, certamente, um ideal para a humanidade. Ao contrário, a diversidade que torna iguais os desiguais e transplanta a noção de igualdade para o tratamento jurídico dos desiguais como iguais na sua diversidade é um valor ético que não pode ser menosprezado. 
Em pontos salientados, o Ministro prevê maior rigor na fiscalização dos procedimentos de fertilização in vitro, para os embriões congelados há três anos ou mais, no trato dos embriões considerados "inviáveis", na autorização expressa dos genitores dos embriões e na proibição de destruição dos embriões utilizados, exceto os inviáveis. Para o Ministro Menezes Direito, "as células-tronco embrionárias são vida humana e qualquer destinação delas à finalidade diversa que a reprodução humana viola o direito à vida.

Sobre a liberdade, Adorno (2009, p. 74), destaca ser ela uma das faculdades que mais tipicamente caracteriza o ser humano e está na raiz de sua dignidade intrínseca, o homem está habilitado para decidir por si mesmo, com base na sua razão, significa dizer que os indivíduos humanos não estão programados para determinadas atividades instintivas cujo financiamento ignoram e realizam de modo inevitável. Neste sentindo importante lição traz Diniz (2007, p. 21):

O direito à vida integra-se à pessoa até o seu óbito, abrangendo o direito de nascer, o de continuar vivo e o de subsistência, mediante trabalho honesto (CF, art. 70) ou prestação de alimentos (CF. arts. 5ㅇ, LXVII, e 209), pouco importando que seja idosa (CF. art. 230), nascituro, criança, adolescente (CF. art. 227), portadora de anomalia física ou psíquica (CF, arts. 203, IV $, 227, \S 1$ 이 II), que esteja em coma ou que haja manutenção do estado vital por meio de processo mecânico.

Ademais, não se deve esquecer que as técnicas de fertilização extracorpórea igualmente demonstram que o concepto tem autonomia para engendrar a sua placenta e prover o seu desenvolvimento até mesmo em úteros emprestados, isto é, tem autonomia de desenvolvimento independentemente da maternidade biológica. A respeito desse entendimento, Ferraz (1991, p. 47) leciona que:

Uma coisa é indiscutível: desde o zigoto, o que se tem é vida, diferente do espermatozoide e do óvulo; vida diferente do pai e da mãe, mas vida humana, se pai e mãe são humanos. Pré-embrionária no início embrionária, após, mas vida humana. Em suma, desde a concepção há vida humana nascente, a ser tutelada.
Desde a formação do zigoto, o concepto é um indivíduo humano explorando o seu próprio programa de desenvolvimento, o qual, enquanto genoma é completo e suficiente, ou seja, nada se torna humano se já não o é desde então.

No debate bioético envolvendo as novas tecnologias, destaca-se que deve existir o equilíbrio adequado entre a liberdade e a dignidade da pessoa humana, para que se evite a coisificação do homem, e nesse sentido destaca Adorno (2009, p. 82):

Esta explicação de dignidade se traduz em uma exigência de não instrumentalização da pessoa humana e é sumamente esclarecedora no campo da bioética. Significa por exemplo, que não se pode sacrificar uma vida de uma pessoa para salvar a que precisa de um órgão vital; não se pode submeter um indivíduo a experimento científico sem 0 seu consentimento ou quando o expõe a perigo de vida. Assim, através da exigência de não instrumentalização da pessoa, o princípio da dignidade da pessoa permite fixar limites éticos às intervenções biomédicas no ser humano.

Por sua vez, Habermas (2010, p. 32) alerta sobre o perigo de uma eugenia liberal que possa se desencadear em diagnósticos pré-implantatórios e do uso de embriões para pesquisa:

[...] Não podemos excluir o fato de que o conhecimento de uma programação eugênica do próprio patrimônio hereditário limita a configuração autônoma da vida do indivíduo e mina as relações fundamentalmente simétricas entre pessoas livres e iguais.

A vida humana em si é um valor superior do ordenamento constitucional, é do interesse de todos, necessária à nossa autorreferência como espécie. Os avanços científicos/tecnológicos devem pautar-se aos valores dispostos na constituição. Todo e qualquer avanço tem um preço e esse não pode ser pago com vidas humanas. 


\section{PERSONALIDADE JURÍDICA E O AVANÇO BIOTÉCNOLÓGICO}

Definir o momento da aquisição da personalidade jurídica é uma questão que engloba grandes discussões no ordenamento jurídico pátrio. 0 sistema jurídico brasileiro adotou a teoria natalista sob o entendimento de que após o nascimento com vida há personalidade e consequentemente direitos, e que o nascituro tem apenas expectativas de direitos.

Morin $(2015$, p. 216) traz uma importante reflexão acerca do relacionamento médico e paciente, em que o indivíduo tratado é compreendido como um paciente, mas ignorado como pessoa, sendo ele isolado de sua natureza humana.

Apesar de estar previsto na teoria natalista proteção ao nascituro, não significa que a mesma, garanta a personalidade dele, adotando-se tal teoria, passaria a tratar o embrião, como coisa, o qual não se admite frente ao princípio da dignidade da pessoa humana.

$\mathrm{Na}$ teoria concepcionista a personalidade é augurada desde a concepção. Ou seja, embora ainda não tenha nascido, o nascituro é pessoa por estar sendo gerado. É inegável direitos ao nascituro na atual conjuntura. A respeito da teoria Habermas (2010, p. 44) aduz que "segundo essa concepção, todo exemplar biologicamente determinável da espécie deve ser considerado como uma pessoa em potencial e como um portador de direitos fundamentais".

Para Habermas (2010, p. 33) os progressos científicos da genética molecular direcionam as características humanas que possuímos por natureza, cada vez mais à área das intervenções biotécnicas. Esse método do ponto de vista das ciências naturais experimentais sucede à familiar tendência de tornar progressivamente disponível o ambiente natural.

O STF no voto da relatoria na ADI 3510 resguardou que a proteção à vida humana deve ser proporcional ao seu fortalecimento, o que deveria ser analisado ao contrário, visto que quanto mais frágil a vida mais carente de proteção, podendo citar como exemplo o princípio da proteção integral à criança e ao adolescente previsto no art. 227 da Constituição Federal de 1988, uma vez que são seres humanos em processo de desenvolvimento.
Habermas (2010, p. 51-52) aduz, ainda que em algumas fases da vida humana sejam consideradas não pessoal, devem ser consideradas com dignidade e respeito:

[...] O caráter dos entraves morais, difíceis de definir, que regulam o trato com a vida humana antes do nascimento e após a morte explica a escolha de expressões semanticamente flexíveis. A vida humana também desfruta, em suas formas anônimas, de "dignidade" e exige "respeito". Se podemos recorrer ao termo "dignidade", é porque ele cobre um amplo espectro semântico e apenas evoca o conceito mais específico da "dignidade humana.

A personalidade é construída pelas características próprias da pessoa humana, conjunto de elementos que formam um indivíduo e psicologicamente diferenciado de outro. Os direitos da personalidade, são essenciais à toda pessoa. São direitos inatos, tendo o Estado que os reconhecer em plano legislativo constitucional ou ordinária.

Dessa maneira, estar guarnecido de personalidade, é ter aptidão e capacidade para adquirir e exercer seus direitos, qualidade de se considerar pessoa, sem esgotar e delimitar o que seja conceito de pessoa humana, visto que personalidades humanas decorrem durante toda a vida de um processo de autoconhecimento do homem. Sobre o tema Diniz (2003, p. 135) faz um breve comentário:

São direitos subjetivos da pessoa de defender o que lhe é próprio, ou seja, a sua integridade física (vida, alimentos, próprio corpo vivo ou morto, corpo alheio vivo ou morto); a sua integridade intelectual (liberdade de pensamento, autoria científica, artística e literária) e sua integridade moral (honra, recato, segredo pessoal, profissional e doméstico, imagem, identidade pessoal, familiar e social).

No art. 5o da Constituição Federal de 1988 está previsto o direito à vida, integrando o rol de direitos e garantias fundamentais do homem, sem este direito é impossível se falar em qualquer outro direito, visto que é essencial a existência do sujeito de direito. 
A vida humana é o bem mais importante do indivíduo, sendo ilícita a violação da dignidade deste por norma infraconstitucional. Dessa maneira, o direito civil é que deveria ser entendido conforme a constituição, e não o contrário. A fertilização do óvulo humano é o princípio importante de um sistema de desenvolvimento individualizado e controlado por si próprio.

As manipulações genéticas podem causar no futuro da espécie humana grandes consequências, nos levando a certificar até que ponto nossos pensamentos têm nos conduzido, dessa maneira Habermas (2010, p. 59-60) faz uma plausível reflexão:

A manipulação da composição do genoma humano, progressivamente decifrado, e a expectativa de muitos pesquisadores de genes de em breve poder controlar a evolução abalam a distinção categorial entre o subjetivo e o objetivo, entre o que cresce naturalmente e o que é fabricado em esferas que até o momento não estiveram à nossa disposição.

É de grande importância salientar, que a problematização não é a técnica, mas sim o alcance e o modelo de seu emprego, isso poderia modificar nossa percepção ética de espécie, e que a consciência moral seria também afetada.

A respeito, Habermas (2010, p. 61), relata que a não apresentação de negativas de ordem moral a intervenções na estrutura genética de integrantes influentes de nossa comunidade moral é estimada pela maneira que as intervenções serão realizadas.

A vida de uma pessoa, tem valor superior dentro do ordenamento jurídico e é do interesse de todos. No direito brasileiro ainda não há regulamentação de controle da técnica, e com os avanços tecnológicos devem modelar-se com base nos valores inscritos na constituição. No tocante Morin (2015, p. 225) diz que:

O desenvolvimento da auto-observação pessoal, que poderia favorecer a reforma da educação e a reforma de vida compreenderia também o auto exame do funcionamento, dos hábitos, das incapacidades de seu próprio corpo. $O$ "Conhece-te a ti mesmo" não seria mais apenas psicológico, mas também biológico. (Grifo do autor)
Existe a possibilidade de os pais fazerem o diagnóstico pré-implantatório e não implantarem a vida enferma. A gravidez de modo algum teve a certeza de tornar-se o que foi planejado pelos pais. Habermas (2010, p. 43) ensina que:

[...] No outro caso, a proteção de vida do feto entra em conflito com as considerações dos pais, que, ponderando a questão como se fosse um bem material, desejam ter um filho, mas recusam a implantação se o embrião não corresponder a determinados padrões de saúde. Nesse conflito, os pais não são envolvidos de improviso; eles aceitam desde o princípio o embate ao mandarem fazer exame genético do embrião. Esse tipo de controle deliberado da qualidade coloca um novo aspecto em jogo - a instrumentalização de uma vida humana, produzida sob condições e em função de preferências e orientações axiológicas de terceiros.

É possível observar que a vida do embrião é renunciada pelos pais, seja por não desejarem certas características genéticas, por não fruir de recursos de plano econômico e social que permitam a estes pais educar seus filhos e dar á estes, sendo pessoas portadoras de doença ou deficiência o tratamento médico indispensável para que a pessoa tenha uma vida digna.

Mas quanto aqueles que decidem modificar a estrutura genética de uma pessoa, Habermas (2010, p. 75), instrui que devem ter a consciência de que futuramente poderá ocorrer conflitos, visto que quando um indivíduo em processo de crescimento passar a ter conhecimento das características que outra pessoa projetara para ele, a fim de modificar as peculiaridades em sua constituição genética, a perspectiva de ter sido fabricado pode sobrepor a de um corpo que cresce naturalmente.

A liberdade e a igualdade remetem um ao outro no pensamento político e para uma vida digna para o ser humano, tais institutos são valores que fundamentam a democracia, no entanto, necessitase verificar as condições para sua efetivação, e como permitir que alguém decida que outrem não deve viver ou não deva ser, de maneira a coibir a crença de perfeição sobre o ser humano. 


\section{CONCLUSÃO}

Os avanços tecnológicos obtidos nos últimos tempos pelos seres humanos têm ocasionado grandes mudanças sociais, a incansável busca pelo aperfeiçoamento humano, tema de grande importância e tratado por todas as ciências, revelam o desejo do homem pela perfeição na busca de seus anseios.

O embrião ainda não é detentor de direitos da personalidade quando no período entre a fertilização in vitro e a implantação in útero, ou seja, a proteção será concedida ao embrião segundo o regulamento ético/jurídico que lhe seja atribuído, sendo que a proteção legal deve superar ao nascimento, desde o momento da concepção.

$\mathrm{Na}$ atual conjuntura, o anseio de se ter um filho "perfeito", sem anomalias incentivou e intensificou a busca de intervenções biotecnológicas de aprimoramento genético, o que por algumas vezes é inconstitucional por não se pautar em princípios fundamentais humanos.

A busca em satisfazer a própria vontade com uso desenfreado dos avanços biotecnológicos, pode acarretar num conflito de interesses. O Direito deve alcançar os avanços em tempo de apresentar uma interpretação judicial coerente.

Com o avanço no campo genético e a falta de regulamentação e controle sobre a reprodução assistida através do diagnóstico pré-implantacional, garante aos pais a escolha de implantar ou não o embrião, o que acarreta o desperdício de vidas humanas e a primazia de uma pessoa sobre a outra, o que difere ao princípio da dignidade da pessoa humana, o qual é inerente a todos, sem peculiaridades.

O Diagnóstico pré-implantacional é benéfico se com sua utilização o objetivo seja terapêutico, não ofendendo a integralidade do embrião e na tentativa de evitar uma gravidez de riscos.

Por fim conclui-se que, a vida e a liberdade são alguns dos atributos mais importantes inerentes ao ser humano, devem ser protegidos por todos e pelo Estado de direito, se há vida há necessidades e direitos a serem garantidos a esta, os seres humanos carregam desde sua criação uma intrínseca qualidade superior à de outras espécies, sendo uma vida tão importante quanto a outra.

\section{BIBLIOGRAFIA}

ADORNO, Roberto. Liberdade, e dignidade da pessoa. Dois paradigmas opostos ou complementares da bioética? In: Bioética e responsabilidade. COSTA, Judith Martins; MOLLER, Letícia Ludwig. (orgs). Rio de Janeiro: Forense, 2009, p.73-93;

DINIZ, Maria Helena. 0 estado atual do bi direito. São Paulo: Saraiva 2007;

FERRAZ, Sérgio. Manipulações biológicas e princípios constitucionais: uma introdução. Porto Alegre, Fabris, 1991;

HABERMAS, Jurgen. 0 futuro da natureza humana. A caminho de uma eugenia liberal? Trad. Karina Janini. São Paulo: Martins Fontes, 2010;

MARTINS-COSTA, Judith, MÖLLER, Ludwig, L. Bioética e Responsabilidade. Disponível em: https://integrada.minhabiblioteca.com.br/\#/books /978-85-309-5606-6/. Acesso em: 13 abr. 2020.

MORIN, Edgard. A via para o futuro da

humanidade. Tradução de Edgard de Assis

Carvalho; Mariza Perassi Bosco. 2. ed. Rio de Janeiro: Bertrand Brasil, 2015.

SALES, Ramiro Gonçalves, Alcântara, Regis Luiz Jordão. Diagnóstico Genético de Pré-Implantação, Dignidade da pessoa humana e Eugenia Liberal. Disponível em:

http://www.publicadireito.com.br/artigos/?cod=52 c5189391854c93. Acesso em 18 abr. 2020.

SARLET, Ingo Wolfgang. A eficácia dos direitos fundamentais: Uma teoria geral dos direitos fundamentais na perspectiva constitucional. 12.ed.rev.atual e ampl. Porto Alegre; Livraria do Advogado Editora, 2015. 